\title{
ANALISIS PEMILIHAN SUPPLIER DENGAN MENGGUNAKAN METODE ANALYTICAL HIERARCHY PROCESS ( Studi Kasus PT.Gunung Naga Mas )
}

\author{
Riko Ervil ${ }^{1}$,Fandy Rahman ${ }^{2}$ \\ Program Studi Teknik Industri, Sekolah Tinggi Teknologi IndustriPadang \\ $\underline{\text { rikopdg01@gmail.com }}^{1}$, fandyrhmn.fr@gmail.com $^{2}$
}

\begin{abstract}
Abstrak: Pemilihan supplier adalah hal yang sangat penting yang harus dilakukan dalam aktivitas pembelian dan pemenuhan bahan baku bagi sebuah perusahaan. Pembelian atau pengadaan memiliki nilai penting bagi perusahaan dalam rangka pemenuhan persediaan, baik berupa komponen dan bahan baku yang diperlukan perusahaan yang berkualitas. Penelitian ini bertujuan untuk menentukan kriteria-kriteria supplier yang sesuai dengan standar perusahaan, serta memilih supplier karton yang baik untuk PT. Gunung Naga Mas. Teknik analisa data yang digunakan adalah Analytic Hierarchy Process(AHP). Diperlukan penyusunan struktur hirarki masalah, menghitung Eigenvalue dan Eigenvector, menghitung konsistensi, dan menghitung prioritas. Dari penelitian ini didapatkan hasil bahwasanya kriteria pertama yang paling berpengaruh dalam pemilihan supplier karton pada PT. Gunung Naga Mas adalah kriteria ketepatan pengiriman didapat hasil bobot 0,247. Prioritas kedua yaitu kriteria kualitas didapat bobot 0,205. Kemudian, kriteria ketiga adalah ketepatan jumlah dengan bobot 0,203 . Selanjutnya kriteria layanan pada prioritas keempat dengan bobot 0,196 , dan terakhir kriteria harga menjadi prioritas kelima dengan bobot 0,149 . Berdasarkan kriteria dalam pemilihan supplier pada penelitian ini didapatkan hasil bahwa PT. Sumatera Kemasindo dinilai sebagai supplier terbaik dengan nilai bobot 0,438. Prioritas selanjutnya adalahPT. Cahaya Alam Sejatidengan nilai bobot 0,354 dan prioritas terakhir adalah PT. KKM dengan nilai bobot 0,208.
\end{abstract}

Kata kunci:Pemilihan supplier, AHP, Kriteria Supplier, Teknik Analisa

Abstract: Supplier selection is a very important thing that must be done in purchasing activities, in order to fulfill raw materials for company. Purchasing or procurement has important value for the company in the context of fulfilling inventory, both in the form of quality components and raw materials. This research aims to determine supplier criteria in accordance with company standards, in order to choosing a good cardboard supplier for PT. Gunung Naga Mas. The data analysis technique used is the Analytic Hierarchy Process (AHP). In this technique It is necessary to figure the problem hierarchy structure, calculate eigenvalue and eigenvector, calculate consistency, and calculate priorities. This research, it was calculate the first criteria that most influential for supplier is the accuracy of delivery, obtained results 0.247 . The second priority is the quality criteria obtained results 0.205 . The third criterion is the the exact amount to sent obtained results 0.203 . Furthermore, the service criteria at the fourth priority obtained result 0.196, and price criteria becomes the fifth priority obtained results 0.149. Based on all the criteria, in this research PT. Sumatra Kemasindo is rated as the valuable supplier with obtained value of 0.438. The next priority is PT. Natural True Light with a obtained value 0.354 and the last is PT. KKM with a weight value of 0.208.

Keywords: Suppliers Selection, AHP, Supplier Criteria, Analysis Technique

\section{PENDAHULUAN}

Untuk mengambil keputusan dalam memilih supplier, pengambil keputusan (decision maker) juga membutuhkan alat untuk menganalisis dalam memecahkan masalah yang bersifat kompleks sehingga keputusan yang diambil lebih berkualitas. Pemilihan supplier harus dilakukan secara teliti karena dapat menyebabkan 
terganggunya proses produksi dan operasional perusahaan jika pemilihan supplier tidak teliti.

Pada tabel 1 dibawah ini dapat dilihat permasalahan yang terjadi pada saat ini pada supplier yang ada.

Tabel 1

\section{Data Permaslah Supplier Tahun 2018}

\begin{tabular}{|c|c|c|c|}
\hline $\mathrm{N}_{0}$ & $\begin{array}{c}\text { Nama } \\
\text { Perusahaan }\end{array}$ & $\begin{array}{c}\text { Jenis } \\
\text { bahan } \\
\text { baku }\end{array}$ & Permasalahan \\
\hline \multirow{5}{*}{1} & \multirow{5}{*}{$\begin{array}{c}\text { PT. } \\
\text { Sumatera } \\
\text { Kemasindo }\end{array}$} & \multirow{5}{*}{ karton } & $\begin{array}{c}\text { Karton tipis, wama gambar agak terang, mudah } \\
\text { dilipat. }\end{array}$ \\
\hline & & & Jumlah bahan baku hanya untuk 5 hari kerja. \\
\hline & & & Pengiriman terlambat sampai 2 hari. \\
\hline & & & Harga lebih murah. \\
\hline & & & Karton ada yang tidak dilem dan sobek. \\
\hline \multirow{5}{*}{2} & \multirow{5}{*}{ PT. KKM } & \multirow{5}{*}{ karton } & $\begin{array}{l}\text { Karton tebal, warna gambar terlalu gelap, susah } \\
\text { dilipat, ukuran karton agak kecil. }\end{array}$ \\
\hline & & & Jumlah bahan baku hanya untuk 4 hari kerja. \\
\hline & & & Pengiriman terlambat sampai 3 hari. \\
\hline & & & Harga lebih mahal. \\
\hline & & & Karton ada yang polos, tidak dilem, sobek. \\
\hline \multirow{5}{*}{3} & \multirow{5}{*}{$\begin{array}{l}\text { PT. Cahaya } \\
\text { Alam Sejati }\end{array}$} & \multirow{5}{*}{ karton } & $\begin{array}{l}\text { Karton tebal, warna gambar cukup bagus, mudah } \\
\text { dilipat. }\end{array}$ \\
\hline & & & Jumlah bahan baku hanya untuk 4 hari kerja. \\
\hline & & & Pengiriman terlambat sampai 3 hari. \\
\hline & & & Harga tidak terlalu mahal. \\
\hline & & & Karton ada yang sobek, gambar timpang. \\
\hline
\end{tabular}

Selanjutnya dapat dilihat pada tabel 2 secara detail tentang data bahan baku cacat dan keterlambatan waktu pengiriman bahan baku dari setiap supplier yang ada pada saat ini. Dari pertimbangan tersebut diataslah maka dilakukan penelitian ini yang bertujuan untuk menentukan kriteriakriteria supplier yang sesuai dengan standar perusahaan dan memilih supplier yang baik untuk PT. Gunung Naga Mas.

Agar didapat supplier yang berkualitas, maka Salah satu metode yang bisa digunakan untuk pemilihan supplier adalah metode AHP (Analytical Hierarchy Process). Metode AHP ini membantu memecahkan persoalan yang kompleks dengan menstruktur suatu hirarki kriteria, pihak yang berkepentingan, hasil dan dengan menarik berbagai pertimbangan guna mengembangkan bobot atau prioritas. Metode ini juga menggabungkan kekuatan dari perasaan dan logika yang bersangkutan pada berbagai persoalan, lalu mensintesis berbagai pertimbangan yang beragam menjadi hasil yang cocok dengan perkiraan kita secara intuitif sebagaimana yang dipresentasikan pada pertimbangan yang telah dibuat (Rahmayanti, 2010).

Tabel 2

Data Cacat dan Keterlambatan Pengiriman Bahan Baku

\begin{tabular}{|c|c|c|c|c|c|}
\hline Bulan & $\begin{array}{l}\text { Permintaan } \\
\text { (Dus) }\end{array}$ & Nama Perusahaan & $\begin{array}{c}\text { Bahan } \\
\text { Baku } \\
\text { Datang } \\
\text { (dus) }\end{array}$ & $\begin{array}{c}\text { Bahan } \\
\text { baku } \\
\text { cacat } \\
(\%)\end{array}$ & $\begin{array}{c}\text { Keterlam } \\
\text {-batan ( } \\
\text { hari) }\end{array}$ \\
\hline \multirow{4}{*}{ Mei } & \multirow{4}{*}{162500} & $\begin{array}{l}\text { PT. Sumatera } \\
\text { Kemasindo }\end{array}$ & 36400 & $0.14 \%$ & 2 \\
\hline & & PT. KKM & 39000 & $0.19 \%$ & 3 \\
\hline & & PT. Cahaya Alam Sejati & 55900 & $0.15 \%$ & 3 \\
\hline & & Jumlah & 131300 & $0.48 \%$ & 8 \\
\hline \multirow{4}{*}{ Juni } & \multirow{4}{*}{123500} & $\begin{array}{l}\text { PT. Sumatera } \\
\text { Kemasindo }\end{array}$ & 24700 & $0.30 \%$ & 2 \\
\hline & & PT. KKM & 42900 & $0.23 \%$ & 3 \\
\hline & & PT. Cahaya Alam Sejati & 46800 & $0.20 \%$ & 3 \\
\hline & & Jumlah & 114400 & $0.74 \%$ & 8 \\
\hline \multirow{4}{*}{ Juli } & \multirow{4}{*}{226200} & $\begin{array}{l}\text { PT. Sumatera } \\
\text { Kemasindo }\end{array}$ & 52000 & $0.10 \%$ & 2 \\
\hline & & PT. KKM & 70200 & $0.11 \%$ & 3 \\
\hline & & PT. Cahaya Alam Sejati & 52000 & $0.12 \%$ & 3 \\
\hline & & Jumlah & 174200 & $0.32 \%$ & 8 \\
\hline \multirow{4}{*}{ Agustus } & \multirow{4}{*}{183300} & $\begin{array}{l}\text { PT. Sumatera } \\
\text { Kemasindo }\end{array}$ & 54600 & $0.09 \%$ & 2 \\
\hline & & PT. KKM & 36400 & $0.23 \%$ & 3 \\
\hline & & PT. Cahaya Alam Sejati & 37050 & $0.20 \%$ & 3 \\
\hline & & Jumlah & 128050 & $0.53 \%$ & 8 \\
\hline
\end{tabular}

Sumber : PT. Gunung Naga Mas, 2018

Metode ini mengikut sertakan ukuran kualitatif dan kuantitatif. AHP adalah metode pengambilan keputusan yang dikembangkan untuk pemberian prioritas pada beberapa alternatif ketika beberapa kriteria harus dipertimbangkan, serta mengijinkan pengambil keputusan untuk menyusun masalah yang kompleks ke dalam suatu bentuk hirarki atau serangkaian level yang terintegrasi.

\section{METODE PENELITIAN}

Metode Analytic Hierarchy Process (AHP) dikembangkan oleh Prof.Thomas Lorie Saaty dari Wharston Business School. Metode ini dikembangkan untuk mencari ranking atau urutan prioritas dari berbagai alternatif dalam pemecahan suatu 
permasalahan. Pada metoda ini diperlukan penentuan prioritas dan uji konsistensi terhadap pilihan-pilihan yang telah dilakukan.

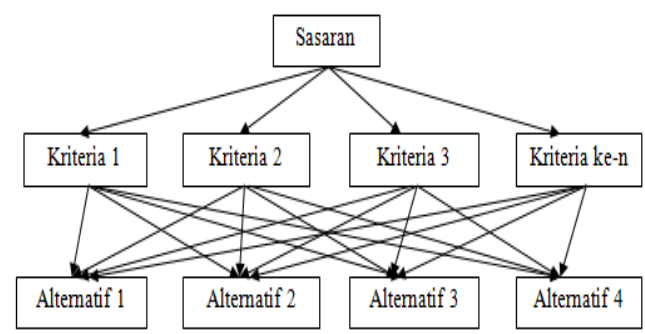

Gambar 1. Struktur Hirarki AHP

Agar tujuan penelitian tercapai, maka penulis menggunakan langkahlangkah yang harus dilakukan pada tahapan AHP sebagai berikut :

1. Mengidentifikasi kriteria-kriteria supplier yang sesuai dengan standar perusahaan, dimana urutan langkahlangkahnya adalah sebagai berikut:

a. Menyusun struktur hirarki masalah dalam metode AHP, kriteria biasanya disusun dalam bentuk hirarki.

b. Membuat matriks perbandingan berpasangan yang menggambarkan kontribusi relatif pengaruh setiap elemen terhadap masing-masing tujuan kriteria yang setingkat di atasnya.

c. Langkah selanjutnya yang harus dilakukan adalah melakukan perhitungan bobot atau prioritas dari masing-masing kriteria seperti harga, kualitas, layanan, ketepatan pengiriman, dan ketepatan jumlah. Dimana tahapan yang harus dilakukan adalah sebagai berikut :

1. Membuat perbandingan berpasangan dari masing-masing kriteria.

Tabel 3

Perbandingan Berpasangan

\begin{tabular}{|l|l|l|l|l|l|}
\hline C & A1 & A2 & A3 & $\cdots$ & An \\
\hline A1 & A11 & A12 & A13 & & A1n \\
\hline A2 & A21 & A21 & A21 & & A2n \\
\hline A3 & A31 & A31 & A31 & & A3n \\
\hline$\cdots$ & & & & & \\
\hline An & An1 & An2 & An3 & & Ann \\
\hline
\end{tabular}

2. Desain Kuesioner

Kuesioner merupakan suatu alat yang digunakan untuk mengumpulkan data dengan cara memberikan dan menyebarkan sejumlah pertanyaan kepada responden dengan harapan memberikan respon atas pertanyaanpertanyaan tersebut. Adapun tujuan pokok pembuatan kuisioner adalah untuk memperoleh informasi yang relevan serta informasi dengan tingkat validitas dan reliabilitas setinggi mungkin. Dalam penelitian ini metoda yang digunakan untuk pembuatan kuesioner adalah metoda Garvin dimana ada delapan dimensi kualitas yaitu (Dewi, 2009).

3. Penilaian yang diperoleh dari responden kemudian dirata-rata menggunakan geometric mean. Secara matematis teori rata-rata geometrik dirumuskan sebagai berikut :

$$
a i j=(Z 1, Z 2, Z 3, \ldots ., Z n)^{1 / n}
$$

Keterangan :

aij $=$ Nilai rata-rata perbandingan berpasangan kriteria Ai dengan

Aj untuk n partisipan.

$\mathrm{Zi}=$ Nilai perbandingan antara $\mathrm{Ai}$ dengan Aj untuk partisipan i, dengan $\mathrm{i}=1,2,3, \ldots, \mathrm{n}$. $\mathrm{n}=$ jumlah partisipan .

4. Hasil yang didapat dari setiap perbandingan berpasangan ditampilkan dalam matriks perbandingan berpasangan (pairwise comparison).

5. Lakukan pembagian masing-masing elemen pada kolom tertentu dengan nilai jumlah kolom tersebut.

6. Hasil pembagian pada poin 4 tersebut diatas kemudian dinormalisasi untuk mendapatkan vector eigen matriks dengan cara menghitung rata-rata jumlah baris terhadap lima kriteria. 
7. Selanjutnya melakukan perhitungan Rasio konsistensi dengan langkah sebagai berikut:
a. Melakukan perkalian nilai matriks perbandingan awal dengan bobot.
b. Melakukan perkalian jumlah baris dengan bobot.
c. Melakukan perhitungan $\lambda$ maks dengan menjumlahkan hasil perkalian di atas dibagi dengan $n$.

$$
\lambda \mathbf{m a k s}=\sum \mathbf{v} / \mathbf{n}
$$

d. Melakukan perhitungan Indeks konsistensi.Dalam pengambilan keputusan, sangat penting untuk mengetahui konsistensi dari sebuah persepsi. Adapun indikator dari konsistensi dapat diukur melalui CI yang dirumuskan :

$$
\mathbf{C I}=(\boldsymbol{\lambda} \text { maks }-\mathbf{n}) /(\mathbf{n}-\mathbf{1})
$$

Keterangan :

$\mathrm{CI}=$ indeks konsistensi

$\lambda$ maks $=$ eigenvalue maksimum

$\mathrm{n}=$ orde matriks

e. Selanjutnya melakukan perhitungan Rasio Konsistensi AHP yang mengukur konsistensi secara menyeluruh dari berbagai pertimbangan melalui suatu rasio konsistensi yang dirumuskan sebagai berikut:

\section{$\mathbf{C R}=\mathbf{C I} / \mathbf{R I}$}

Keterangan :

$$
\begin{aligned}
& \mathrm{CR}=\text { Rasio Konsistensi } \\
& \mathrm{RI}=\text { Indeks random }
\end{aligned}
$$

Dimana nilai RI yang didapatdapat dilihat pada tabel 2.3. Jika nilai $\mathrm{CR}<0,1$ maka nilai perbandingan berpasangan pada matriks kriteria yang diberikan konsisten. Jika nilai CR > 0,1 maka nilai perbandingan berpasangan pada matriks kriteria yang diberikan tidak konsisten. Sehingga harus dilakukan ulang pengisian nilai-nilai pada matriks berpasangan pada unsur kriteria maupun alternative.

a. Menghitung Indeks konsistensi. Dalam persoalan pengambilan keputusan, penting untuk mengetahui konsistensi dari sebuah persepsi. Adapun indikator dari konsistensi dapat diukur melalui CI yang dirumuskan :

$$
C I=(\lambda \text { maks }-\mathbf{n}) /(\mathbf{n}-\mathbf{1})
$$

Keterangan :

$\mathrm{CI}=$ indeks konsistensi

$\lambda$ maks $=$ eigenvalue maksimum

$\mathrm{n}=$ orde matriks

b. Menghitung Rasio Konsistensi AHP mengukur konsistensi menyeluruh dari berbagai pertimbangan melalui suatu rasio konsistensi yang dirumuskan :

$$
\mathbf{C R}=\mathbf{C I} / \mathbf{R I}
$$

Keterangan :

$\mathrm{CR}=$ Rasio Konsistensi

$\mathrm{RI}=$ Indeks random

c. Setelah menghitung bobot atau prioritas dari masing-masing subkriteria dan alternatif supplier, kemudian ditentukan prioritas global dengan cara mengalikan prioritas dari masing-masing subkriteria dengan prioritas kriteria.

d. Setelah mengetahui bobot dari masing-masing subkriteria dan bobot dari masing-masing supplier kemudian ditentukan supplier yang akan dipilih. Nilai keseluruhan dari masing-masing supplier yaitu jumlah keseluruhan dari perkalian bobot supplier dengan bobot subkriteria. Supplier yang dipilih adalah supplier yang memiliki nilai paling tinggi. 


\section{HASIL DAN PEMBAHASAN}

Agar didapat supplier yang baik, maka perlu dilakukan perhitungan bobot atau prioritas kepentingan dari masing-masing variabel seperti harga, kualitas, ketepatan pengiriman, ketepatan jumlah dan layanan. Dilakukan perhitungan dari kuesioner yang diberikan kepada responden yang berjumlah 30 orang. Setelah penilaian tersebut didapatkan, kemudian hasilnya dirata-rata menggunakan rata-rata geometric. Hasil perhitungan dapat dilihat pada tabel 4 berikut :

Tabel 4

Penilaian Prioritas Kepentingan Kriteria Dalam Pemilihan Supplier

\begin{tabular}{|c|c|c|c|c|c|}
\hline & Harga & Kualitas & $\begin{array}{c}\text { Ketepatan } \\
\text { Pengiriman }\end{array}$ & $\begin{array}{c}\text { Ketepatan } \\
\text { Jumlah }\end{array}$ & Layanan \\
\hline Harga & 1 & 1.236 & 0.378 & 0.501 & 0.864 \\
\hline Kualitas & 0.809 & 1 & 0.901 & 1.505 & 1.017 \\
\hline $\begin{array}{c}\text { Ketepatan } \\
\text { Pengirima }\end{array}$ & 2.646 & 1.110 & 1 & 1.158 & 0.964 \\
\hline $\begin{array}{c}\text { Ketepatan } \\
\text { Jumlah }\end{array}$ & 1.995 & 0.665 & 0.864 & 1 & 1.037 \\
\hline Layanan & 1.116 & 0.983 & 1.000 & 0.964 & 1 \\
\hline
\end{tabular}

Dari hasil perhitungan perbandingan berpasangan antar variabel diatas maka diperoleh bobot yang dapat dilihat pada tabel 5 dibawah ini :

Tabel 5

\section{Bobot Prioritas Kepentingan Kriteria} Dalam Pemilihan Supplier

\begin{tabular}{|c|c|c|}
\hline Kriteria & bobot & Prioritas \\
\hline Harga & 0.149 & V \\
\hline Kualitas & 0.205 & II \\
\hline $\begin{array}{c}\text { Ketepatan } \\
\text { Pengiriman }\end{array}$ & 0.247 & I \\
\hline $\begin{array}{c}\text { Ketepatan } \\
\text { Jumlah }\end{array}$ & 0.203 & III \\
\hline Layanan & 0.196 & IV \\
\hline
\end{tabular}

Agar memudahkan proses penulisan, pengumpulan data dan pengolahan data, maka perlu dilakukan penyingkatan inisial pada supplier yang ada pada PT. Gunung Naga Mas. Dimana inisial tersebut adalah : PT. Sumatera Kemasindo dengan inisian supplier X, PT. KKM dengan inisial supplier Y dan PT. Cahaya Alam Sejati dengan inisial $\mathrm{Z}$.
Langkah selanjutnya yang perlu dilakukan adalah mendapatkan bobot secara keseluruhan dari kriteria yang ada. Langkah yang dapat dilakukan untuk memperolehbobot atau prioritas lokal maka perlu dilakukan perhitungan nilai bobot globalnya terlebih dahulu. Hasil nilai bobot global dapat dilihat pada tabel 6 .

Tabel 6

\section{Prioritas Global (Global Priority)}

\begin{tabular}{|c|c|c|c|c|c|}
\hline Level 0 & Level 1 & Level 2 & \multirow{2}{*}{ Bobot } & Level 3 & \multirow{2}{*}{ Bobot } \\
\hline Tujuan & Kriteria & Subkriteria & & Alternatif & \\
\hline \multirow{27}{*}{$\begin{array}{c}\text { Memilih } \\
\text { Supplier } \\
\text { Terbaik }\end{array}$} & \multirow[b]{3}{*}{ Harga } & \multirow{3}{*}{ H1 } & \multirow{3}{*}{0.107} & Supplier X & 0.052 \\
\hline & & & & Supplier Y & 0.023 \\
\hline & & & & Supplier Z & 0.033 \\
\hline & \multirow[t]{3}{*}{0.149} & \multirow{3}{*}{$\mathrm{H} 2$} & \multirow{3}{*}{0.042} & Supplier X & 0.018 \\
\hline & & & & Supplier Y & 0.008 \\
\hline & & & & Supplier Z & 0.015 \\
\hline & \multirow{9}{*}{$\begin{array}{c}\text { Kualitas } \\
0.205\end{array}$} & \multirow{3}{*}{ Q1 } & \multirow{3}{*}{0.082} & Supplier X & 0.040 \\
\hline & & & & Supplier Y & 0.015 \\
\hline & & & & Supplier Z & 0.027 \\
\hline & & \multirow{3}{*}{ Q2 } & \multirow{3}{*}{0.055} & Supplier X & 0.025 \\
\hline & & & & Supplier Y & 0.010 \\
\hline & & & & Supplier Z & 0.020 \\
\hline & & \multirow{3}{*}{ Q3 } & \multirow{3}{*}{0.068} & Supplier X & 0.031 \\
\hline & & & & Supplier Y & 0.012 \\
\hline & & & & Supplier Z & 0.025 \\
\hline & \multirow{3}{*}{$\begin{array}{l}\text { Ketepatan } \\
\text { Pengiriman }\end{array}$} & \multirow{3}{*}{ D1 } & \multirow{3}{*}{0.182} & Supplier X & 0.077 \\
\hline & & & & Supplier Y & 0.037 \\
\hline & & & & Supplier Z & 0.068 \\
\hline & \multirow[t]{3}{*}{0.247} & \multirow{3}{*}{ D2 } & \multirow{3}{*}{0.065} & Supplier X & 0.025 \\
\hline & & & & Supplier Y & 0.016 \\
\hline & & & & Supplier Z & 0.025 \\
\hline & \multirow{3}{*}{\multicolumn{2}{|c|}{ Ketepatan Jumlah }} & \multirow{3}{*}{0.203} & Supplier X & 0.092 \\
\hline & & & & Supplier Y & 0.039 \\
\hline & & & & Supplier Z & 0.071 \\
\hline & \multirow{3}{*}{\multicolumn{2}{|c|}{ Layanan }} & \multirow{3}{*}{0.196} & Supplier X & 0.078 \\
\hline & & & & Supplier Y & 0.048 \\
\hline & & & & Supplier Z & 0.070 \\
\hline
\end{tabular}

Selanjutnya menghitung bobot masingmasing alternatif secara keseluruhan dengan cara menjumlahkan semua bobot keseluruhan pada masing-masing supplier. Hasil penjumlahan dari bobot dapat dilihat pada tabel 7 dibawah ini :

Tabel 7

Bobot Alternatif Secara Keseluruhan

\begin{tabular}{|c|c|c|}
\hline Alternatif & Bobot & Prioritas \\
\hline Supplier X & 0.438 & I \\
\hline Supplier Y & 0.208 & III \\
\hline Supplier Z & 0.354 & II \\
\hline
\end{tabular}

Selanjutnya melakukan pengukuran konsistensi, hal ini dimaksudkan untuk melihatketidakkonsistenan respon yang 
diberikan responden. Sehingga jika tidakkonsisten, maka pengisian nilai-nilai pada matriks berpasangan pada unsurkriteria maupun alternatif harus diulang.

Nilai konsistensi rasio (CR) dari penilaian responden dapat dilihat pada Tabel 8 dibawah ini.

\section{Tabel 8}

Consistensi Ratio (CR) Penilaian Responden

\begin{tabular}{|l|c|c|}
\hline \multicolumn{1}{|c|}{ Perbandingan Berpasangan } & CR & Keterangan \\
\hline Antar kriteria (level 1) & 0.037 & konsisten \\
\hline Antar subkriteria harga & 0.000 & konsisten \\
\hline Antar subkriteria kualitas & 0.097 & konsisten \\
\hline Antar subkriteria ketepatan pengiriman & 0.000 & konsisten \\
\hline Antar alternatif terhadap subkriteria H1 & 0.066 & konsisten \\
\hline Antar alternatif terhadap subkriteria H2 & 0.031 & konsisten \\
\hline Antar alternatif terhadap subkriteria Q1 & 0.047 & konsisten \\
\hline Antar alternatif terhadap subkriteria Q2 & 0.066 & konsisten \\
\hline Antar alternatif terhadap subkriteria Q3 & 0.081 & konsisten \\
\hline Antar alternatif terhadap subkriteria D1 & 0.049 & konsisten \\
\hline Antar alternatif terhadap subkriteria D2 & 0.096 & konsisten \\
\hline Antar alternatif terhadap kriteria ketepatan jumlah & 0.090 & konsisten \\
\hline Antar alternatif terhadap kriteria layanan & 0.077 & konsisten \\
\hline
\end{tabular}

Pada tabel 8 diatas menunjukkan bahwa semua penilaian responden konsisten, dan tidak perlu diulang lagi.

\section{KESIMPULAN}

Dari hasil perhitungan menggunakan metode AHP, maka dapat disimpulkan sebagai berikut.

1. Berdasarkan tabel 2, kriteria yang sangat berpengaruh dalam pemilihan supplier karton pada PT. Gunung Naga Mas adalah kriteria ketepatan pengiriman dengan bobot 0,247. Prioritas kedua yaitu kriteria kualitas dengan bobot 0,205. Kemudian, kriteria ketepatan jumlah pada prioritas ketiga dengan bobot 0,203 . Selanjutnya kriteria layanan pada prioritas keempat dengan bobot 0,196, dan terakhir kriteria harga pada prioritas kelima dengan bobot 0,149 .

2. Berdasarkan nilai bobot dari kriteriadansubkriteriadalamtabel 4, didapat hasil PT. Sumatera Kemasindo dinilai sebagai supplier terbaik dan dapat dijadikan supplier jangka panjang dengan nilai bobot 0,438. Prioritas selanjutnya adalah PT. Cahaya Alam Sejati dengan nilai bobot 0,354 dan prioritas terakhir adalah PT. KKM dengan nilai bobot 0,208

\section{DAFTAR KEPUSTAKAAN}

Andalia, Winny, Irnanda Pratiwi,

Analisis Pemilihan Supplier Menggunakan Metode Analytical Hierarchy Process(Studi Kasus PT. Perkasa Sejahtera Mandiri), Integrasi : Jurnal Ilmiah Teknik Industri, Vol.3, N0.1, Universitas Tridinanti, Palembang, 2018

Heimlich,Joe E andHook Paula, A History Of Packaging.http://wikipedia.com.

Diakses pada tanggal 13 September 2018.

Maria, Armandina Belo, Joko Susetyo dan Endang Widuri Asih. 2016. Analisis Pemilihan Supplier Bahan Baku Untuk Produksi Dengan Metode Analytic Hierarchy Process (AHP). ISSN: $\quad 2338-7750, \quad$ Fakultas Teknologi Industri, Institut Sains \& Teknologi AKPRIND Yogyakarta, 2016

Nyoman, I Pujawan dan ER, Mahendrawati, Supply Chain Management, Institut Teknologi Sepuluh November Surabaya, Guna Widya, Surabaya, 2010.

Permenkes RI No. 492/MENKES/PER/IV/2010.

Pengertian Air Minum Dalam Kemasan(AMDK),http://bardowen ang.blogspot.com/2010/04/prokontr 
a air murni dan air mineral.html, Diakses pada tanggal 30 September 2018.

Riko, Ervil, Mela Rosalina,Estimasi Permintaan Air Minum Dalam Kemasan AYIA Cup 240 ml Pada PT. Gunung Naga Mas, Jurnal Pendidikan Teknologi Kejuruan Vol 2 No 2 2019, Fakultas Teknik Universitas Negeri Padang, 2019

Standar Mutu Karton PT. Gunung Naga Mas, Padang , 2015

Saaty, Thomas L.Decision Making for Leaders: The Analytical Hierarchy Process for Decisions in a Complex World, Belmont, California: Wadsworth. ISBN 0-534-97959-9; 1982, Paperback, Pittsburgh: RWS. ISBN 0-9620317-4"Focuses on practical application of the AHP; briefly covers theory."

Saaty, Thomas L.; Peniwati, Kirti, Group Decision Making: Drawing out and Reconciling Differences. Pittsburgh, Pennsylvania: RWS Publications. ISBN 978-1-88860308-8., 2008

Shinta W.H, Nelmi Sebrina, Analisis Pemilihan Supplier Pupuk Npk Dengan Metode Analytical Hierarchy Process (AHP), Jurnal Inovasi Bisnis, Vol.5 No.2, Politeknik Negeri Batam, Batam, 2017.

Sugiyono, Metodologi Penelitian Kualitatif, kuantitatif, dan R\&D, Alfabeta, Bandung, 2017

Tri Sumardi, Riko, Ervil,Service Quality Measurement For Medical Treatment Utilize ServqualFuzzy, International Conference On Global Education III, ISBN 978602-70525-1-2, 1156, 2015 